(inclusive) moves. The latter classes are stored as a bitmap, which is economical because they contain a rather limited number of initial positions.

Thus, the playing database compresses to some 160 Kbytes. Allowing for bootstrap, etc., 120 Kbytes on the floppy are free for other uses. The playing program consults the floppy, addressing it by block, and displays the message 'drawn' or 'mate-in-n', followed, if won, by the optimal white moves and their optimal black countermoves.

\title{
THE KBBKN STATISTICS: NEW DATA FROM KEN THOMPSON
}

\section{H.J. van den Herik and I.S. Herschberg}

Delft University of Technology The Netherlands

Elsewhere in this issue (p. 4), Michie and Bratko exhibit a histogram showing their count of the KBBKN positions by distance-to-win. While their histogram is enlightening, a database result by Ken Thompson allows even stronger quantification. In Table 2 below, wfreq counts the number of legal WTM positions starting from which a mate is obtained or conversion into a proper subgame is enforced. Each proper subgame (KBBK or KBKN) is known to be won, provided it has arisen from KBBKN. [Note that the general $\mathrm{KBKN}$ endgame is not won, but instances arising by optimal play out of a won KBBKN do enjoy this property.]

In the subsidiary Table $1, m f r e q$ counts the number of positions with the stated distance-to-mate for all proper subgames in the sense defined above. It is not directly comparable to statistics published elsewhere, because it runs over both proper subgames only and therefore fails to be complete for KBBK. Moreover, it also is suspected of containing an unknown proportion of KBKN positions. However, Ken Thompson assures us that the latter are isolated positions not leading to an extended sequence of moves. Furthermore, we note that the results of Table 2, when referring to conversion rather than to direct mate, are silent on the point of entry into Table 1 . Specifically, by way of example, a distance of $m$ in Table 2 implies, if conversion is its endpoint, that the distance-to-mate is $m+n$ with $n \leq 19$, but unspecified otherwise.

Finally, we beg readers to note that Table 1 requires most careful interpretation : apart from being possibly contaminated with $\mathrm{KBKN}$, Table 1 is known to be deficient, because it fails to enumerate all KBBK positions, merely counting those which legally and optimally arise out of KBBKN.

\begin{tabular}{|r|r||r|r|}
\hline $\begin{array}{l}\text { Proper subgames } \\
\text { of KBBKN won } \\
\text { in \# of moves }\end{array}$ & $\begin{array}{l}\text { \# of positions } \\
m f r e q\end{array}$ & $\begin{array}{l}\text { Proper subgames } \\
\text { of KBBKN won } \\
\text { in \# of moves }\end{array}$ & $\begin{array}{l}\text { \# of positions } \\
m f r e q\end{array}$ \\
\hline 1 & 1580 & 11 & 62414 \\
2 & 652 & 12 & 73646 \\
3 & 3734 & 13 & 88690 \\
4 & 4608 & 14 & 90134 \\
5 & 7668 & 15 & 79014 \\
6 & 9378 & 16 & 61518 \\
7 & 14202 & 17 & 27340 \\
8 & 21554 & 18 & 3362 \\
9 & 31066 & 19 & 30 \\
10 & 45314 & & \\
\hline
\end{tabular}

Table 1: $m f r e q$ counts the number of positions in the proper subgames of KBBKN with their distance-to-mate 


\begin{tabular}{|c|c|c|c|}
\hline $\begin{array}{l}\text { KBBKN posi- } \\
\text { tions won in } \\
\text { \# of moves }\end{array}$ & \# of positions wfreq & $\begin{array}{l}\text { KBBKN posi- } \\
\text { tions won in } \\
\# \text { of moves }\end{array}$ & \# of positions wfreq \\
\hline 1 & 11642102 & 34 & 253160 \\
\hline 2 & 1643300 & 35 & 243250 \\
\hline 3 & 1956612 & 36 & 217750 \\
\hline 4 & 981564 & 37 & 186492 \\
\hline 5 & 650824 & 38 & 147468 \\
\hline 6 & 548594 & 39 & 120278 \\
\hline 7 & 471194 & 40 & 105624 \\
\hline 8 & 405244 & 41 & 99356 \\
\hline 9 & 341974 & 42 & 100906 \\
\hline 10 & 297426 & 43 & 108608 \\
\hline 11 & 264432 & 44 & 135884 \\
\hline 12 & 241638 & 45 & 195826 \\
\hline 13 & 231814 & 46 & 289670 \\
\hline 14 & 224488 & 47 & 392776 \\
\hline 15 & 233084 & 48 & 486966 \\
\hline 16 & 245486 & 49 & 581756 \\
\hline 17 & 255044 & 50 & 684892 \\
\hline 18 & 260242 & 51 & 788752 \\
\hline 19 & 261164 & 52 & 920868 \\
\hline 20 & 257792 & 53 & 1016772 \\
\hline 21 & 253790 & 54 & 1037140 \\
\hline 22 & 240404 & 55 & 981394 \\
\hline 23 & 228990 & 56 & 859132 \\
\hline 24 & 222536 & 57 & 721244 \\
\hline 25 & 227280 & 58 & 579930 \\
\hline 26 & 240616 & 59 & 43014 \\
\hline 27 & 268216 & 60 & 2692 \\
\hline 28 & 299594 & 61 & 115298 \\
\hline 29 & 323922 & 62 & 26052 \\
\hline 30 & 333916 & 63 & 2804 \\
\hline 31 & 318030 & 64 & 9 \\
\hline 32 & 296328 & 65 & 2 \\
\hline 33 & 275448 & 66 & \\
\hline
\end{tabular}

Table $2:$ wfreq counts the number of legal WTM-won-KBBKN positions with their distance-to-win 